\title{
Anti-allergic effects of a nonameric peptide isolated from the intestine gastrointestinal digests of abalone (Haliotis discus hannai) in activated HMC-1 human mast cells
}

\author{
SEOK-CHUN KO ${ }^{1,6^{*}}$, DAE-SUNG LEE ${ }^{2 *}$, WON SUN PARK ${ }^{3 *}$, JONG SU YOO $^{2}$, MI-JIN YIM ${ }^{2}$, \\ ZHONG-JI QIAN ${ }^{4}$, CHANG-MIN LEE $^{5}$, JUNGHWAN OH $^{1,6}$, WON-KYO JUNG $^{1,6}$ and IL-WHAN CHOI ${ }^{1,7}$ \\ ${ }^{1}$ Marine-Integrated Bionics Research Center, Pukyong National University, Busan; ${ }^{2}$ Converging Research Division, \\ National Marine Biodiversity Institute of Korea, Seochun, Chungcheongnam-do; ${ }^{3}$ Department of Physiology, \\ Kangwon National University School of Medicine, Chuncheon, Gangwon, Republic of Korea; ${ }^{4}$ Key Laboratory
} of Advanced Processing of Aquatic Products of Guangdong Higher Education Institution, College of Food Science and Technology, Guangdong Ocean University, Zhanjiang, Guangdong, P.R. China; ${ }^{5}$ Department of Molecular Microbiology and Immunology,

Warren Alpert School of Medicine Box G-L, Providence, RI, USA; ${ }^{6}$ Department of Biomedical Engineering, and Center for Marine-Integrated Biomedical Technology (BK21 Plus), Pukyong National University;

${ }^{7}$ Department of Microbiology, College of Medicine, Inje University, Busan, Republic of Korea

Received July 2, 2015; Accepted November 20, 2015

DOI: $10.3892 / \mathrm{ijmm} .2015 .2420$

\begin{abstract}
The aim of the present study was to examine whether the intestine gastrointestinal (GI) digests of abalone [Halioti $s$ discus hannai (H. discus hannai)] modulate inflammatory responses and to elucidate the mechanisms involved. The GI digests of the abalone intestines were fractionated into fractions I ( $>10 \mathrm{kDa})$, II $(5-10 \mathrm{kDa})$ and III $(<5 \mathrm{kDa})$. Of the abalone intestine GI digests (AIGIDs), fraction III inhibited the passive cutaneous anaphylaxis (PCA) reaction in mice. Subsequently, a bioactive peptide [abalone intestine GI digest peptide (AIGIDP)] isolated from fraction III was determined to be $1175.2 \mathrm{Da}$, and the amino acid sequence was found to be PFNQGTFAS. We noted that the purified nonameric peptide (AIGIDP) attenuated the phorbol-12-myristate 13-acetate plus calcium ionophore A23187 (PMACI)-induced histamine release and the production of pro-inflammatory cytokines, such as tumor necrosis factor- $\alpha$ (TNF- $\alpha$ ), interleukin (IL)-1 $\beta$ and IL-6 in
\end{abstract}

Correspondence to: Professor Il-Whan Choi, Department of Microbiology, College of Medicine, Inje University, 75 Bokji-Ro, Busanjin-gu, Busan 614-735, Republic of Korea

E-mail: cihima@inje.ac.kr

Professor Won-Kyo Jung, Department of Biomedical Engineering and Center for Marine-Integrated Biomedical Technology (BK21 Plus), Pukyong National University, 45 Yongso-ro, Nam-gu, Busan 608-737, Republic of Korea

E-mail: wkjung@pknu.ac.kr

*Contributed equally

Key words: abalone, Haliotis discus hannai, gastrointestinal digest, peptides, pro-inflammatory cytokines, histamine human mast cells (HMC-1 cells). In addition, we also noted that AIGIDP inhibited the PMACI-induced activation of nuclear factor- $\kappa \mathrm{B}(\mathrm{NF}-\kappa \mathrm{B})$ by suppressing $\mathrm{I} \kappa \mathrm{B} \alpha$ phosphorylation and that it suppressed the production of cytokines by decreasing the phosphorylation of JNK. The findings of our study indicate that AIGIDP exerts a modulatory, anti-allergic effect on mast cell-mediated inflammatory diseases.

\section{Introduction}

Shellfish, such as mussels, clams and abalones are a commercially important bioresource in the fishery and food industries. Abalone is a marine gastropod, as well as an important shellfish and industrial resource in Asia, Africa, Australia and America, and approximately 100 species of abalones are to be found worldwide $(1,2)$. Of the abalone species, the Pacific abalone, Haliotis discus hannai (H.discus hannai), is the most commercially important species in Korea. H. discus hannai abalone mariculture has expanded in land- and sea-based systems, and the total yield from Korea was estimated at 7,580 metric tons in 2009. Korea is one of the major suppliers of abalone, and the majority of the Korean production is in the remote Wando region (3). In addition, the production of various types of abalone (e.g., dried, steamed, seasoned and spiced) has also significantly increased (14).

Marine organism-derived proteins and peptides possess various biological activities, such as, anticoagulant (4), antimicrobial (5) and antihypertensive (6) activities, and they have also been shown to reduce the risk of developing cardiovascular disease (7). Depending on the composition and the molecular size of the amino acid, bioactive peptides can be involved in diverse biological functions (8). During gastrointestinal (GI) digestion, proteolytic digestion can generate absorbable and bioactive peptides in the stomach and 
small intestinal tract $(9,10)$ that may have certain physiological benefits. Certain recent studies have reported that in vitro GI digests of marine organisms possess biological activities that are as potent as those of other natural antioxidants $(11,12)$. In our recent studies, we demonstrated that the intestinal digests of abalone, $H$. discus hannai, possess potent antioxidant and anti-inflammatory activities, and inhibit the effects of matrix metalloproteinases (MMPs) $(13,14)$.

Allergic diseases such as asthma, allergic rhinitis and atopic dermatitis are typified by an undesirable reaction to a normally harmless allergen in the environment (15). Allergens can enter the body through various routes, such as inhalation, ingestion or external skin contact (16). An allergy is a condition characterized by the excessive recruitment of lymphocytes, basophils, eosinophils and mast cells to the inflamed site of lesions (17). Of these cells, mast cells are central effector cells involved in the pathogenesis of allergic diseases (18). Mast cells are commonly found at sites exposed to the external environment, namely the skin and mucosal membranes $(19,20)$. Mast cells constitutively express the high-affinity receptor for immunoglobulin (Ig) $\mathrm{E}$ (FceRI) on their surface, and the number of surface FceRI is positively regulated by ambient concentrations of $\operatorname{IgE}(21)$. The IgE-dependent activation of mast cells, through the aggregation of FceRI by allergen-specific IgE, initiates a complex secretory response. Once activated, mast cells release and generate biologically active preformed and newly synthesized mediators, such as granule-associated mediators, cytokines and inflammatory lipids, which can initiate the immediate hypersensitivity responses associated with allergies (17).

In the present study, abalone intestines were digested using an in vitro GI digestion system containing pepsin, trypsins and $\alpha$-chymotrypsin. The abalone intestine GI digests (AIGIDs) produced by the GI digestion system were fractionated into AIGID I (>10 kDa), II (5-10 kDa) and III ( $<5 \mathrm{kDa})$ using an ultrafiltration (UF) membrane system. We evaluated the antiallergic effects of AIGIDs on IgE-dependent passive cutaneous anaphylaxis (PCA) reactions in vivo, and we investigated the regulatory mechanisms underlying the pharmacological effects of abalone intestine GI digest peptide (AIGIDP) on the release of phorbol-12-myristate 13-acetate (PMA) plus calcium ionophore A23187 (PMACI)-induced inflammatory mediators in human mast cells (HMC-1).

\section{Materials and methods}

Animals. Male (6 to 8-week-old) ICR mice were purchased from Orient Bio Inc. (Seoul, Korea) and were allowed to acclimatize to our animal facility for at least 1 week. All experimental animals used in this study were maintained under a protocol approved by the Institutional Animal Care and Use Committee of the Inje University Medical School.

Materials.Live adult abalones (H.discus hannai) were collected from Wando island, Wando-gun, Korea. PMA, calcium ionophore A23187 (calcimycin; C29H37N3O6), anti-dinitrophenol (DNP) IgE, DNP-human serum albumin (HSA) and Iscove's modified Dulbecco's medium (IMDM) were all purchased from Sigma Chemical Co. (St. Louis, MO, USA). Nuclear factor- $\kappa \mathrm{B}$ (NF- $\mathrm{\kappa B}$ ) antibody was obtained from eBioscience (San Diego, CA, USA) (Cat. no. 14-6731). Antibodies against JNK (Cat. no. 9252), phosphorylated (p-)JNK (Cat. no. 9251), p-extracellular signal-regulated kinase (ERK)1/2 (Cat.no. 9106),p-p38 mitogen-activated protein kinase (MAPK) (Cat. no. 9211) and p-IкB $\alpha$ (Cat. no. 9246) were all purchased from Cell Signaling Technology, Inc. (Danvers, MA, USA). Antibodies against ERK1/2 (Cat. no. sc-94), p38 MAPK (Cat. no. sc-535), and IкB $\alpha$ (cat. no. sc-371) were all purchased from Santa Cruz Biotechnology, Inc. (Santa Cruz, CA, USA).

\section{Preparation of in vitro GI digestion and fractionation on a} UF membrane bioreactor system. For the digestion process, we used the method previously described by Kapsokefalou and Miller (22). One hundred milliliters of $4 \%$ (w/v) abalone intestine solution were brought to $\mathrm{pH} 2.2$ in gastric digestion (phase I) using $1 \mathrm{M} \mathrm{HCl}$ and $1 \mathrm{M} \mathrm{NaOH}$ while being vigorously mixed. Pepsin was added at an enzyme-to-substrate ratio of $1 / 100(\mathrm{w} / \mathrm{w})$ and then incubated at $37^{\circ} \mathrm{C}$ in a shaker. After $2 \mathrm{~h}$, the $\mathrm{pH}$ was set to 6.5 to mimic the conditions of intestinal digestion (phase II). Similarly, trypsin and $\alpha$-chymotrypsin were both supplemented at an enzyme-to-substrate ratio of $1 / 100(\mathrm{w} / \mathrm{w})$. The solution was further incubated at $37^{\circ} \mathrm{C}$ for $2.5 \mathrm{~h}$. When the samples were taken at the beginning and end of digestion, the $\mathrm{pH}$ was adjusted to 8.0. The samples were centrifuged at $10,000 \mathrm{xg}$ for $15 \mathrm{~min}$ at $4^{\circ} \mathrm{C}$, and the supernatant was lyophilized to obtain an AIGID dry powder. The resultant AIGID was fractionated using a UF membrane bioreactor system with molecular weight (MW) cut-offs (MWCOs) of 1, 5 and $10 \mathrm{kDa}$. Fractionates were designed as follows: AIGID I with MW distribution of $>10 \mathrm{kDa}$, AIGID II with a MW distribution of 5-10 kDa and AIGID III with a MW distribution of $<5 \mathrm{kDa}$. All the AIGIDs recovered from the fractionation were lyophilized in a freeze drier for 5 days.

Cell culture. HMC-1 cells, a human mast cell line, were provided by Professor D. K. Kim (Chonbuk National University, Medical School, Jeonju, Korea). The HMC-1 cells were grown in IMDM and supplemented with $100 \mathrm{U} / \mathrm{ml}$ of penicillin, $100 \mu \mathrm{g} / \mathrm{ml}$ of streptomycin and $10 \%$ fetal bovine serum (FBS) at $37^{\circ} \mathrm{C}$ in an atmosphere with $5 \% \mathrm{CO}_{2}$ with $95 \%$ humidity. The HMC-1 cells were treated with AIGIDP for $30 \mathrm{~min}$. The cells were then stimulated with $50 \mathrm{nM}$ of PMA plus $1 \mu \mathrm{M}$ of A23187 and incubated at $37^{\circ} \mathrm{C}$ for the indicated periods of time.

Determination of cell viability. Cell viability was assessed using the Cell Counting Kit-8 (CCK-8; Dojindo Laboratories, Kumamoto, Japan) assay method. Briefly, wells containing $2 \times 10^{4} \mathrm{cells} /$ well were treated with AIGIDs. Following incubation for $24 \mathrm{~h}$, the cells were washed twice with phosphate-buffered saline (PBS), and CCK- 8 was added to each well and incubated at $37^{\circ} \mathrm{C}$ for $1 \mathrm{~h}$, followed by an analysis at $450 \mathrm{~nm}$ using a microplate reader (model EL800; BioTek, Winooski, VT, USA).

$P C A$ reaction. The mice were injected intradermally with $500 \mathrm{ng}$ of anti-DNP IgE into each of 3 dorsal skin sites that had been shaved $48 \mathrm{~h}$ earlier. The sites were outlined with a waterproof red marker. Forty-eight hours later, each mouse received an injection of $100 \mu \mathrm{g}$ of DNP-HSA in PBS containing $4 \%$ Evans Blue via the tail vein. One hour prior to this injection, the AIGIDs (50 mg/kg, each) were administered intraperitoneally. Thirty minutes after the antigenic challenge, the mice $(n=3)$ 
Table I. Information on primers used for RT-PCR.

\begin{tabular}{lclr}
\hline Genes & NCBI accesion no. & \multicolumn{1}{c}{$5^{\prime} \rightarrow 3^{\prime}$} & Size (bp) \\
\hline IL-1 $\beta$ & NT_022135 & F: TGTCCTGCGTGTTGAAAGATGA & 391 \\
& & R: CAGGCAGTTGGGCATTGGTG & 229 \\
IL-6 & NT_007819 & F: GATGGCTGAAAAAGATGGATGC & \\
& & R: TGGTTGGGTCAGGGGTGGTT & 241 \\
TNF- $\alpha$ & NT_113891 & F: CCCCAGGGACCTCTCTCTAATC \\
& & R: GGTTTGCTACAACATGGGCTACA & 117 \\
GAPDH & NT_009759 & F: CGTCTAGAAAAACCTGCCAA & \\
& & R: TGAAGTCAAAGGAGACCACC & \\
\hline
\end{tabular}

F, forward; R, reverse; GAPDH, glyceraldehyde-3-phosphate dehydrogenase; IL, interleukin. TNF- $\alpha$, tumor necrosis factor- $\alpha$.

were sacrificed by asphyxiation with $\mathrm{CO}_{2}$ and the dorsal skin was removed in order to measure the amount of pigment. The amount of dye was then determined colormetrically following extraction with $1 \mathrm{ml}$ of $0.1 \mathrm{~N} \mathrm{KOH}$ and $9 \mathrm{ml}$ of a mixture of acetone and phosphoric acid (5:13). The absorption intensity of the extraction was measured at $620 \mathrm{~nm}$ using a spectrometer (model ELx800; BioTek).

Histamine assay. The HMC-1 cells were treated with various concentrations of the AIGIDs (100-300 $\mu \mathrm{g} / \mathrm{ml})$ for $30 \mathrm{~min}$ prior to stimulation with PMACI. The amount of histamine was assayed using an enzyme-linked immunosorbent assay (ELISA) kit (Oxford Biomedical Research, Rochester Hills, MI, USA) in accordance with the manufacturer's instructions.

Preparation and identification of the peptide (AIGIDP). AIGID III was loaded onto a HiPrep 16/10 CM FF ion-exchange column (16x100 mm) (from GE Healthcare Life Sciences, Uppsala, Sweden) equilibrated with $20 \mathrm{mM}$ sodium acetate buffer ( $\mathrm{pH}$ 4.0) and eluted with a linear gradient of $\mathrm{NaCl}(0-2 \mathrm{M})$ using fast protein liquid chromatography (FPLC). Pooled and lyophilized fractions were then further purified on a Prime Sphere $10 \mathrm{C} 18$ column (20x250 mm) (Phenomenex, Inc., Torrance, CA, USA) using permeation reverse-phase high-performance liquid chromatography (RP-HPLC) with a linear gradient of acetonitrile (0-35\% in $30 \mathrm{~min}$ ) containing $0.1 \%$ trifluoroacetic acid (TFA). Finally, the accurate molecular mass and amino acid sequence of AIGIDP was ascertained by quadruple time-of-flight mass spectroscopy (Micromass UK Ltd., Altrincham, UK) coupled to an electrospray ionization source.

Cytokine assay. The HMC-1 cells were treated with various concentrations of AIGIDP (100-300 $\mu \mathrm{g} / \mathrm{ml})$ for $30 \mathrm{~min}$ prior to stimulation with PMACI. The levels of interleukin (IL)-1 $\beta$, IL-6, and tumor necrosis factor- $\alpha$ (TNF- $\alpha$ ) were measured using ELISA kits (BioLegend, Inc., San Diego, CA, USA). Quantification of the ELISA results was performed using an ELISA plate reader (Dynatech MR-7000; Dynatech Laboratories Inc., Chantilly, VA, USA) set to a wavelength of $450 \mathrm{~nm}$, according to the manufacturer's instructions.
Reverse transcription-polymerase chain reaction (RT-PCR). Total RNA was isolated using TRIzol reagent (Invitrogen, Carlsbad, CA, USA). Total RNA $(1.0 \mu \mathrm{g})$ from the cells was reverse transcribed using M-MLV reverse transcriptase (Promega, Madison, WI, USA) to produce cDNA. Reverse transcription-generated cDNAs encoding IL-1 $\beta$, IL-6, IL-8 and TNF- $\alpha$ were amplified by PCR using selected primers (Table I). Following amplification, portions of the PCR reactions were electrophoresed on an agarose gel.

Western blot analysis. Western blot analysis was performed according to the method previously described by Yu et al (23). Briefly, the cells were washed 3 times with PBS and lysed with lysis buffer (Mammalian Cell-PE LB; G-Biosciences, St. Louis, MO, USA). Equal amounts of protein were separated on $10 \%$ SDS-polyacrylamide minigels and transferred onto nitrocellulose membranes (Amersham plc., Amersham, UK). Following incubation with the appropriate primary antibody (ERK,

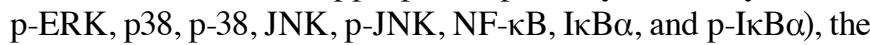
membranes were incubated for $1 \mathrm{~h}$ at room temperature with a secondary antibody conjugated to horseradish peroxidase [goat anti-rabbit IgG (Cat. no. 31460; Pierce Biotechnology, Inc., Rockford, IL, USA), goat anti-mouse IgG (Cat. no. sc-2031; Santa Cruz Biotechnology, Inc.)]. Following 3 washes in Tris-buffered saline Tween-20 (TBST), immunoreactive bands were visualized using the ECL detection system (Pierce Biotechnology, Inc.).

Electrophoretic mobility shift assay. Nuclear extracts were prepared using the NE-PER nuclear extraction reagent (Pierce Biotechnology, Inc.). As a probe for the gel retardation assay, an oligonucleotide harboring the Ig- $\kappa$-chain binding site $\left(\kappa \mathrm{B}, 5^{\prime}-\mathrm{G}\right.$ ATCTCAGAGGGGACTTTCCGAGAGA-3') was synthesized. A non-radioactive method, whereby the 3 ' end of the probe was labeled with biotin, was used in these experiments (Pierce Biotechnology, Inc.). The binding reactions contained $5 \mu \mathrm{g}$ of nuclear extract protein, buffer $(10 \mathrm{mM}$ Tris, $\mathrm{pH} 7.5,50 \mathrm{mM}$ $\mathrm{KCl}, 5 \mathrm{mM} \mathrm{MgCl}_{2}, 1 \mathrm{mM}$ dithiothreitol, $0.05 \%$ Nonidet $\mathrm{P}-40$ and $2.5 \%$ glycerol), $50 \mathrm{ng}$ of poly (dI-dC) and $20 \mu \mathrm{M}$ of biotin-labeled DNA. The reactions were incubated for $20 \mathrm{~min}$ at room temperature in a final volume of $20 \mu \mathrm{l}$. The competition reactions were conducted by adding a 100 -fold 
A

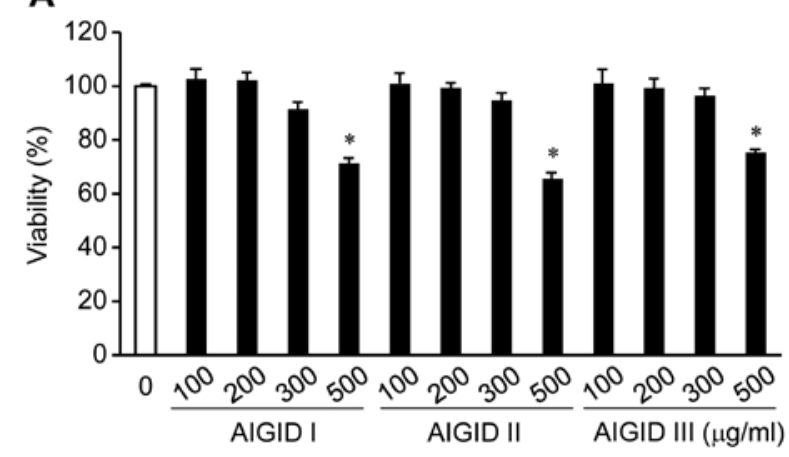

B

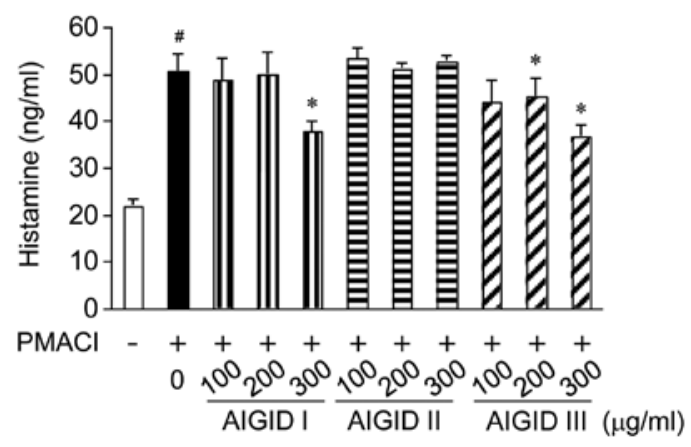

C

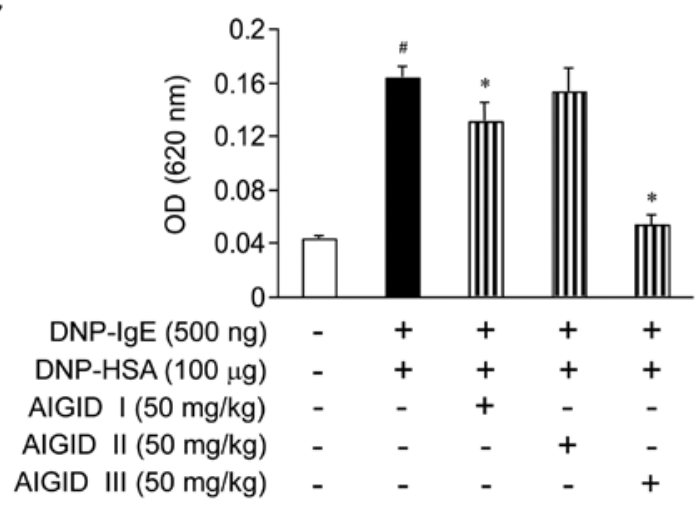

Figure 1. (A) Effect of abalone intestine gastrointestinal digests (AIGIDs) on cytotoxicity to HMC-1 cells. HMC-1 cell viability was evaluated by CCK- 8 assay at $24 \mathrm{~h}$, following treatment with various concentrations of AIGIDs $(100-500 \mu \mathrm{g} / \mathrm{ml})$. Data are presented as the percentage of the untreated control and are the means \pm SEM from at least 3 independent experiments which were performed in triplicate. (B) Effect of AIGIDs on the release of histamine in PMACI-stimulated HMC-1 cells. HMC-1 cells were treated with PMACI for $24 \mathrm{~h}$, and the histamine assay was performed on the supernatant from the cells. Each bar represents the means \pm SEM from 3 independent experiments. ${ }^{\text {"P }}<0.05$, compared with PMACI-unstimulated cell values. ${ }^{*} \mathrm{P}<0.05$, compared with PMACI-stimulated values. (C) Effect of AIGIDs on IgE-mediated passive cutaneous anaphylaxis (PCA) in mice. Anti-dinitrophenyl (DNP) IgE was injected into dorsal skin sites. AIGIDs were intraperitoneally administered $1 \mathrm{~h}$ before a challenge with $100 \mu \mathrm{g}$ of DNP-human serum albumin (HSA). The amounts of dye were extracted and measured by spectrometer. All data are shown as the means \pm SEM from at least 3 independent experiments performed in triplicate. ${ }^{\# P}<0.05$, compared with DNP-IgE and DNP-HSA unstimulated group. ${ }^{*} \mathrm{P}<0.05$, compared with DNP-IgE and DNP-HSA stimulated group.

excess of cold $\kappa \mathrm{B}$ to the reaction mixture. The mixture was then separated by electrophoresis on a $5 \%$ polyacrylamide gel in $0.5 \mathrm{X}$ Tris-borate buffer and transferred onto nylon membranes. The biotin-labeled DNA was detected using a LightShift Chemiluminescent electrophoretic mobility shift assay (EMSA) kit (Pierce Biotechnology, Inc.).
Statistical analysis. Statistical analyses were conducted using the Student's t-test. The results are presented as the means \pm standard error of the mean (SEM) of at least 3 separate experiments. A P-value $<0.05$ was considered to indicate a statistically significant difference.

\section{Results}

Preparation of in vitro GI digestion and fractionation on the UF membrane bioreactor system. In previous studies $(13,14)$, for the formation of AIGIDs, 2 infant formulas, gastric digests (phase 1) and intestinal digests (phase 2) with different biological behaviors were subjected to hydrolysis, a process which simulates physiological digestion. The gastric digests (phase 1) corresponded to a pepsin-hydrolyzed abalone protein-based formula and the intestinal digests (phase 2) to pepsin-hydrolyzed abalone protein by 2 enzymes (trypsin and $\alpha$-chymotrypsin). The abalone intestinal digests (phase 2) were further separated into $3 \mathrm{MW}$ groups, AIGID I ( $>10 \mathrm{kDa})$, II $(5-10 \mathrm{kDa})$ and III $(<5 \mathrm{kDa})$, using UF membranes $(\mathrm{MWCO}=5$ and 10).

Effects of AIGIDs on the viability of HMC-1 cells. We examined the viability of the HMC-1 cells following treatment with 3 types of AIGIDs by CCK-8 assay. No significant cytotoxicity was observed in the HMC-1 cells treated with the AIGIDs at a concentration of up to $300 \mu \mathrm{g} / \mathrm{ml}$; however, cell viability was significantly reduced by $35 \%$ in the cells treated with $500 \mu \mathrm{g} /$ $\mathrm{ml}$ of the AIGIDs (Fig. 1A). Based on these results, a concentration range of $100-300 \mu \mathrm{g} / \mathrm{ml}$ was selected for treatment in the follow-up experiments.

Effect of AIGIDs on the release of histamine from HMC-1 cells. To determine whether AIGIDs inhibit the release of histamine from mast cells, we measured the PMACI-induced histamine release of histamine from HMC-1 cells. The cells were treated with the AIGIDs at concentrations ranging from 100-300 $\mu \mathrm{g} /$ $\mathrm{ml}$ for $1 \mathrm{~h}$ prior to stimulation with PMACI. As shown in Fig. 1B, the release of histamine from the PMACI-treated HMC-1 cells was markedly increased when compared with that of the control group. By contrast, treatment with $300 \mu \mathrm{g} / \mathrm{ml}$ of AIGID I and AIGID III decreased the release of histamine from the cells. However, AIGID II had not significant effect on the release of histamine.

Effects of AIGIDs on the IgE-mediated PCA reaction in mice. To assess the anti-allergic effects of AIGIDs in vivo, we used a mouse model of PCA. Localized extravasation was induced by an injection of DNP-IgE, followed by an antigenic challenge (DNP-HSA). As shown in Fig. 1C, of the AIGIDs, the administration of AIGID III $(50 \mathrm{mg} / \mathrm{kg})$ markedly inhibited in the PCA reaction. These results suggest that AIGID III has more potential than AIGID I or II as an allergy therapeutic. Thus, AIGID III was selected for treatment in the follow-up in vitro experiments.

Purification and identification of the peptide (AIGIDP). AIGID III was purified using chromatographic methods, combining FPLC on a HiPrep 16/10 CM FF ion-exchange column $(16 \times 100 \mathrm{~mm})$ and repeated RP-HPLC on a Prime 


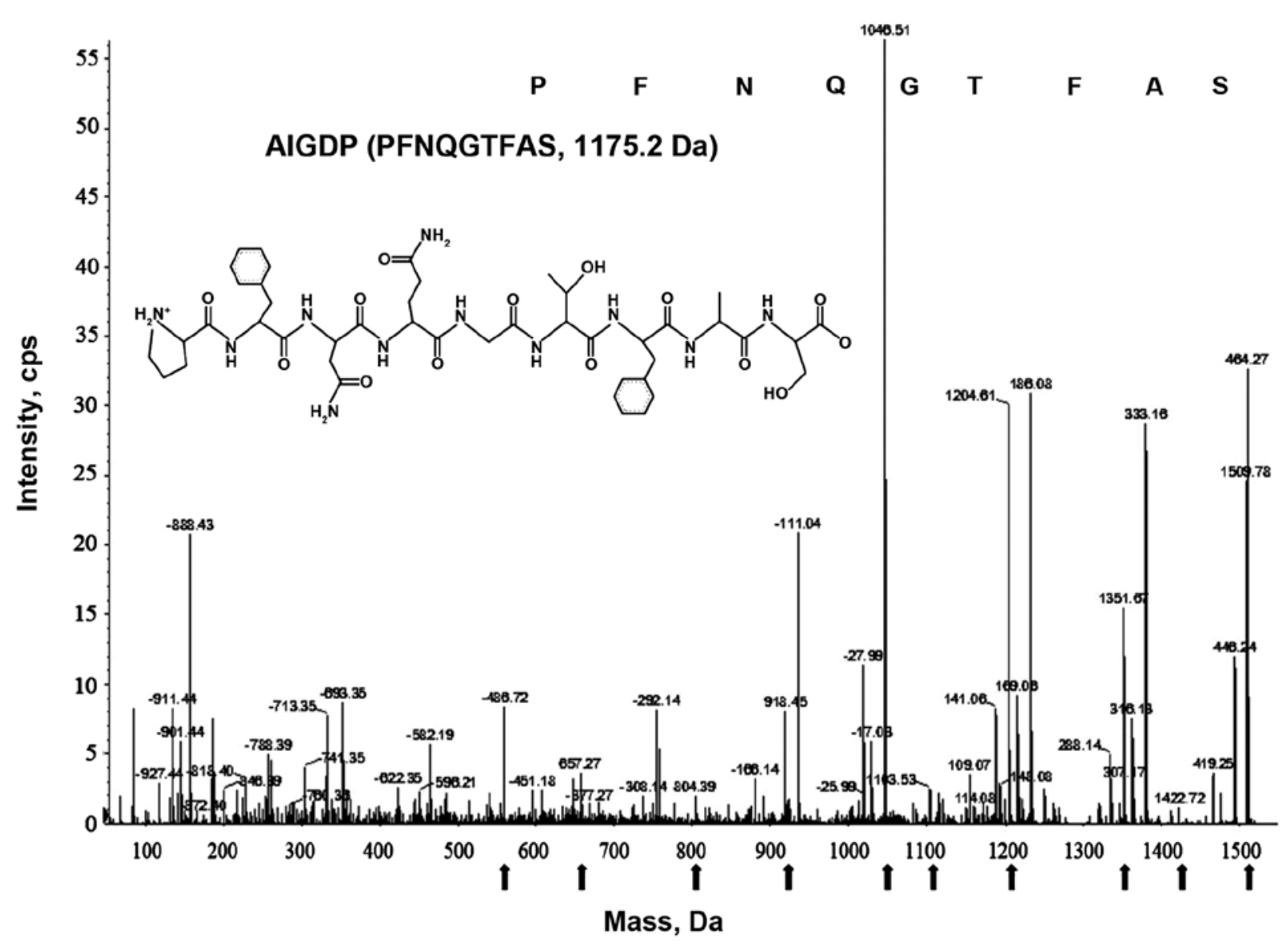

Figure 2. Identification of the molecular mass and amino acid sequence of abalone intestine gastrointestinal digests peptide (AIGIDP). MS/MS experiments were performed on a Q-TOF tandem mass spectrometer equipped with a nano-ESI source. The active peptide was sequenced using the PepSeq de novo sequencing algorithm.

Sphere 10 C18 column (data not shown), as previously described (14). AIGIDP was over $99 \%$ pure according to RP-HPLC and N-terminal sequence analyses. The molecular mass of the peptide (AIGIDP) isolated from AIGID III was determined to be 1175.2 Da by analyzing the ESI/MS spectroscopic data, and its full amino acid sequence was found to be PFNQGTFAS (Fig. 2).

Effect of AIGIDP on the gene expression and secretion of pro-inflammatory cytokines in HMC-1 cells. To examine the effects of AIGIDP on the production of pro-inflammatory cytokines, we treated the cells with AIGIDP (100-300 $\mu \mathrm{g} / \mathrm{ml})$ prior to stimulation with PMACI for $8 \mathrm{~h}$. IL-1 $\beta$, IL- 6 and TNF- $\alpha$ are pro-inflammatory cytokines which play an important role in the immediate hypersensitivity responses associated with allergies (24). Thus, we examined the effects of AIGIDP on the secretion and gene expression of cytokines induced by PMACI in HMC-1 cells by ELISA and RT-PCR. Treatment with AIGIDP suppressed the PMACI-induced mRNA expression of IL-1 $\beta$, IL-6 and TNF- $\alpha$ (Fig. 3A). In addition, the PMACI-induced production of pro-inflammatory cytokines from the mast cells was decreased by treatment with AIGIDP in a dose-dependent manner (Fig. 3B).

Effects of AIGIDP on the activation of MAPKs in PMACI-stimulated HMC-1 cells. In order to elucidate the mechanisms underlying the anti-inflammatory effects of AIGIDP, we examined the activation of MAPKs using western blot analysis. The activation of MAPKs has previously been shown to induce the production of pro-inflammatory cytokines (25). In the present study, we noted that the stimulation of HMC-1 cells with PMACI resulted in the increased phosphorylation of all 3 types of MAPKs: JNK, p38 and ERK1/2. The cells were treated for $30 \mathrm{~min}$ with AIGIDP and then stimulated for 30 min with PMACI. As shown in Fig. 4, treatment with AIGIDP attenuated the PMACI-induced phosphorylation of JNK; however, it did not affect the phosphorylation of ERK1/2 and p38 MAPK.

Effects of AIGIDP on the activation of $N F-\kappa B$ in PMACI-stimulated HMC-1 cells. The expression of proinflammatory cytokines is regulated by the transcription factor, NF- $\kappa \mathrm{B}$ (26). Thus, in order to elucidate the mechanisms through which AIGIDP affects the expression of pro-inflammatory cytokines, we examined the effects of AIGIDP on the activation of NF- $\mathrm{BB}$. The majority of the inhibitors of $N F-\kappa B$ activation exert their effects through the suppression of IкB $\alpha$ phosphorylation and degradation (27). In this study, we found that AIGIDP inhibited the PMACI-induced phosphorylation and degradation of $\mathrm{I} \kappa \mathrm{B} \alpha$, as well as the nuclear translocation of p65 NF-кB (Fig. 5A). Subsequently, we examined the effect of AIGIDP on the DNA-binding activity of NF- $\kappa \mathrm{B}$, using an 
A

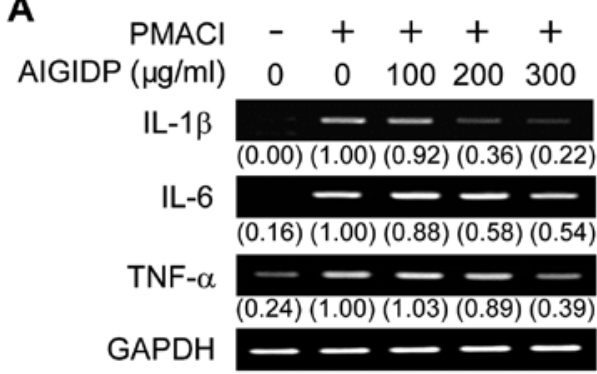

B
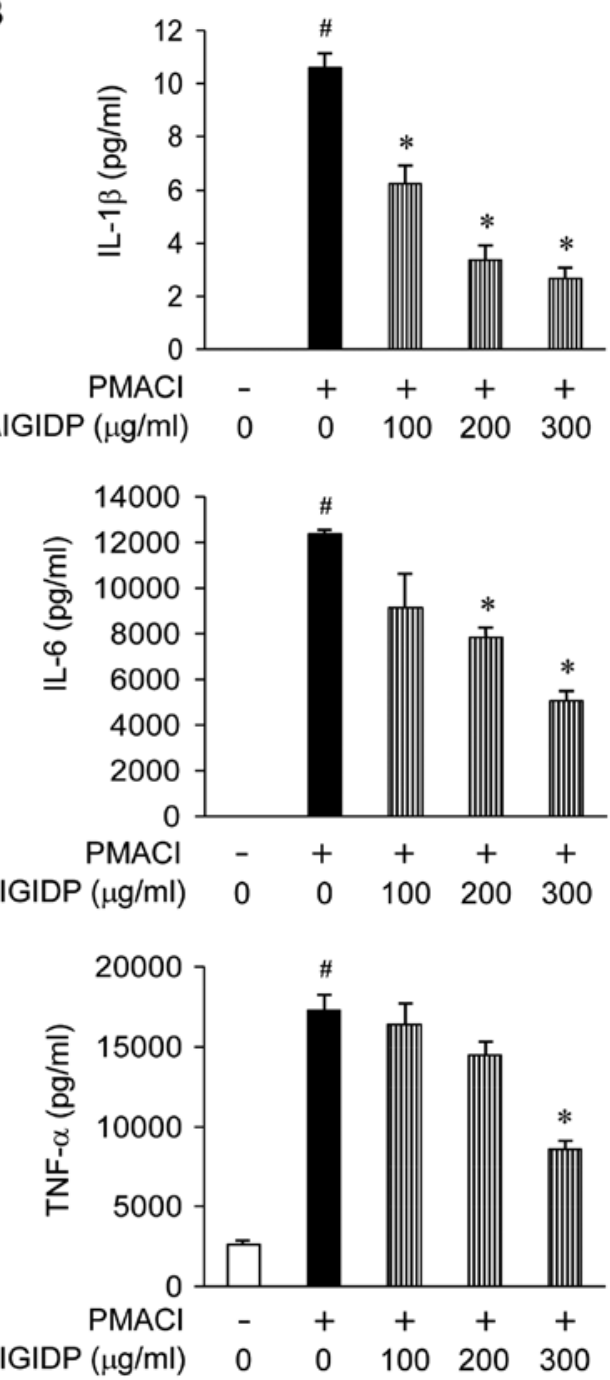

Figure 3. Effect of abalone intestine gastrointestinal digests peptide (AIGIDP) on the expression of pro-inflammatory cytokines in PMACI-stimulated HMC-1 cells. (A) Cells were treated with AIGIDP (100-300 $\mu \mathrm{g} / \mathrm{ml})$ for $1 \mathrm{~h}$ prior to stimulation with PMACI for $6 \mathrm{~h}$. The mRNA expression levels of interleukin (IL)- $1 \beta$, IL- 6 and tumor necrosis factor- $\alpha$ (TNF- $\alpha$ ) were determined by RT-PCR. (B) Cells were treated with AIGIDP (100-300 $\mu \mathrm{g} / \mathrm{ml})$ for $1 \mathrm{~h}$ prior to stimulation with PMACI for $8 \mathrm{~h}$. The protein levels of IL-1 $\beta$, IL- 6 and tumor necrosis factor- $\alpha$ (TNF- $\alpha$ ) were determined by ELISA. Each bar represents the means \pm SEM of 3 independent experiments. ${ }^{~} \mathrm{P}<0.05$, compared with unstimulated cell values. ${ }^{*} \mathrm{P}<0.05$, compared with PMACIstimulated values.

EMSA kit (Fig. 5B). Treatment with PMACI treatment a significant increase in the DNA-binding activity of NF- $\mathrm{KB}$, whereas treatment with AIGIDP markedly reduced the PMACI-induced DNA-binding activity of NF- $\kappa B$.

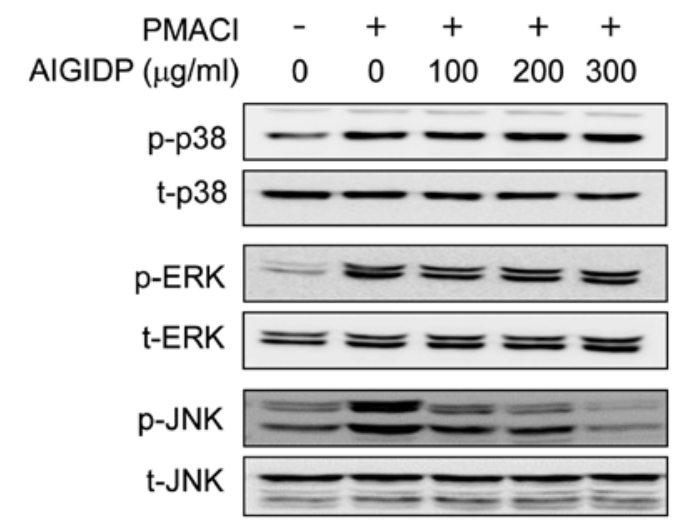

Figure 4. Effect of AIGIDP on the activation of mitogen-activated protein kinases (MAPKs). Following treatment with abalone intestine gastrointestinal digests peptide (AIGIDP) for $1 \mathrm{~h}, \mathrm{HMC}-1$ cells were stimulated with PMA $(50 \mathrm{nM})+\mathrm{A} 23187(1 \mu \mathrm{M})$ for $30 \mathrm{~min}$ for MAPK activation. (A) The phosphorylation of MAPKs was analyzed by western blot analysis.

\section{Discussion}

The human GI tract is composed of the stomach and intestines, and includes all of the organs from the mouth to the anus. The process of digestion converts food into substances that can be easily absorbed and assimilated by the body through the action of digestive enzymes. These enzymes break down proteins into peptides in the GI tract $(28,29)$. Abalone is a marine gastropod and an important resource in the fishery and food industries and is widely cultivated in Asia, Africa, Australia and America. To meet the increasing demand of the Asian market, abalone mariculture has been expanding in land- and sea-based systems in Korea, and the total yield was estimated at 7,580 tons of abalone in 2009 (Marine Institute of Korea) (14). In addition, the manufacture of different types of abalone products (dried, steamed and spiced abalone) has also significantly increased $(13,14)$. It is currently accepted that marine organisms possess various bioactive natural components with a number of physiological functions related to their nutraceutical and pharmaceutical activities such as antioxidant, anti-inflammatory, anti-bacterial, anticoagulant, antifungal, anti-inflammatory, anti-malarial, anti-protozoal, anti-tuberculosis and anti-viral activities (30). In the present study, we digested the abalone intestine using the digestive enzymes, pepsin, trypsin and $\alpha$-chymotrypsin and prepared in vitro GI digests of abalone intestines, a byproduct commonly discarded in the manufacturing process. The AIGIDs were fractionated into $3 \mathrm{MW}$ groups: AIGID I ( $>10 \mathrm{kDa})$, AIGID II (5-10 kDa), and III ( $<5 \mathrm{kDa})$ using a UF membrane system $(\mathrm{MWCO}=5$ and $10 \mathrm{kDa})$.

Mast cells clearly play a central role in the pathogenesis of allergic diseases and participate in both the initiation of the innate immune response and the coordination of the adaptive immune response. Once activated, mast cells release biologically active, preformed mediators. The release of preformed granular mediators, such as histamine, serotonin and $\beta$-hexosaminidase from mast cells is a consequence of complex biochemical events during the process of degranulation (31). Of these granular mediators, histamine has long been known to be a major promoter of allergic inflammatory conditions. Therefore, approaches to controlling the release of histamine may be utilized for the 

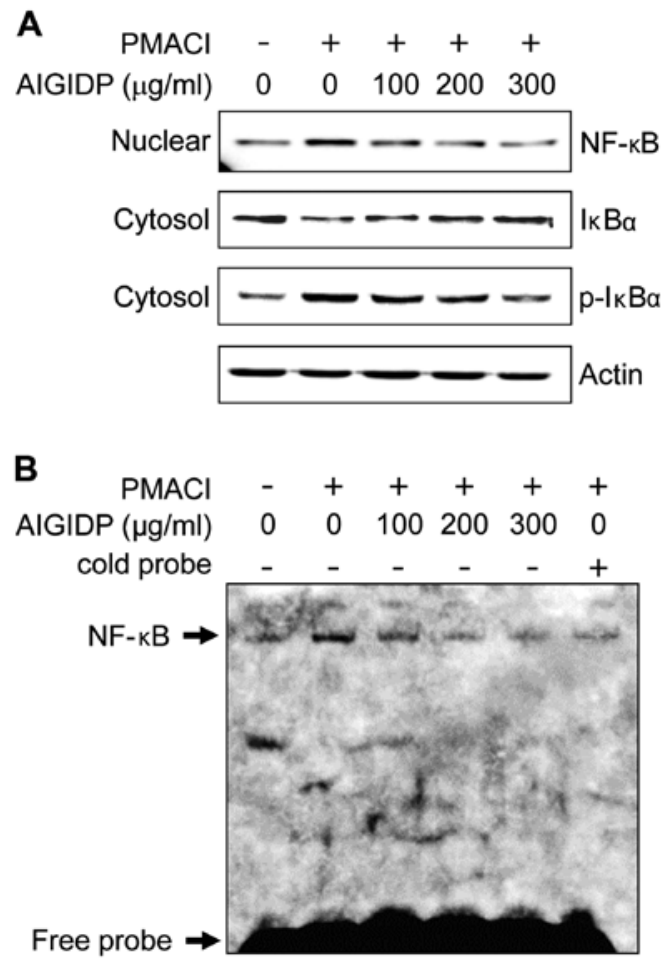

Figure 5. Effect of abalone intestine gastrointestinal digests peptide (AIGIDP) on the phosphorylation and degradation of $\mathrm{I} \kappa \mathrm{B} \alpha$ and nuclear factor- $\kappa \mathrm{B}(\mathrm{NF}-\kappa \mathrm{B})$ activation in PMACI-stimulated HMC-1 cells. HMC-1 cells were pre-treated with AIGIDP (100-300 $\mu \mathrm{g} / \mathrm{ml}$ ) for $30 \mathrm{~min}$ and then stimulated with PMACI for $2 \mathrm{~h}$. (A) The cytosolic extracts were prepared as described in the Materials and

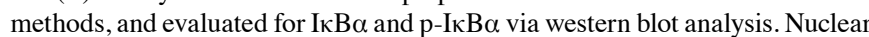
extracts were prepared as described in the Materials and methods, and evaluated for NF- $\kappa$ B via western blot analysis. (B) Nuclear extracts were prepared as described in the Materials and methods, and evaluated for $\mathrm{NF}-\kappa \mathrm{B}$ via EMSA. All data are presented as the means \pm SEM from at least 3 independent experiments, which were performed in triplicate.

management of allergic disorders. In the present study, we investigated the inhibitory effects of fractionated AIGIDs on the PMACI-induced release of histamine from mast cells. Of the separated peptides, AIGID I and AIGID III, but not AIGID II, attenuated the release of histamine in the PMACI-stimulated HMC-1 cells. Subsequently, in order to elucidate the anti-allergic properties of AIGIDs in vivo, we designed a PCA reaction test in mice. PCA can be used in animal models to mimic the IgE-mediated immediate allergic reaction, which is known to be induced by mediators, such as histamine that are secreted from mast cells (32). As shown in Fig. 1C, when the mice were administered 3 types of AIGID peptides, AIGID III exhibited the most promiment suppressive effects on local allergic reactions compared to the other fractions. However, AIGID II did not suppress the allergic reaction activity. These results suggest that AIGID III may be more useful than the other fractions in treating allergic disorders. Additionally, we purified and characterized a peptide (AIGIDP) from AIGID III (Fig. 2). Recently, bioactive peptides from protein hydrolysates have received much attention due to the unraveling of their structural, compositional and sequential properties, as well as their biological activities. They can be used as versatile raw materials for producing nutraceuticals and pharmaceuticals for humans $(33,34)$. The sequence (AIGIDP: PFNQGTFAS, 1175.2 Da) (Fig. 2) is composed of a mixture of essential and non-essential amino acids, with a high concentration of branched chain amino acids (proline) and a low concentration of methionine. This amino acid composition has been specifically formulated to build up tolerance to inflammatory disease as a nutritional supplement. Notably, it has been suggested that bioactive peptides with low molecular weight are able to cross the intestinal barrier (9). Previous research has confirmed that low molecular-weight peptides are involved in potent bioactivities (35). Based on these results, AIGIDP was selected during the screening of antiallergic activity for our follow-up experiments.

Mast cell-derived pro-inflammatory cytokines, such as IL-1 $\beta$, IL- 6 and TNF- $\alpha$ are key indicators of inflammatory allergic disease (36). IL-1 $\beta$ receptor antagonists have been shown to alleviate the late asthmatic reaction in animal models (37). IL-6 is produced from mast cells and can influence B-cell and dendritic cell biology (38). TNF- $\alpha$ has an important amplifying effect in asthmatic inflammation and stimulates airway epithelial cells to produce cytokines (39). Therefore, a reduction in the levels of these pro-inflammatory cytokines is one of the key indicators of an attenuation in allergic inflammatory symptoms.

In the present study, to evaluate the mechanisms responsible for the inhibitory effects of AIGIDP on the production of pro-inflammatory cytokines, we examined the activation of the transcription factor, NF- $\mathrm{BB}$, and MAPKs. The MAPK (JNK, ERK1/2 and p38 MAPK) cascade is one of the important signaling pathways in immune responses, and these pathways play critical roles in the activation, survival and differentiation of, as well as cytokine production in mast cells (40). Therefore, MAPK pathways are appropriate targets for the pharmacological treatment of allergic diseases. In this respect, we examined the inhibitory effects of AIGIDP on the activation of MAPKs in PMACI-stimulated HMC-1 cells. As shown in Fig. 4, AIGIDP inhibited the phosphorylation of JNK, but not that of p38 MAPK and ERK1/2. Many transcription factors have been implicated in the pathophysiology of allergic disease. NF- $\kappa \mathrm{B}$ can be activated by multiple stimuli, such as allergens (41). NF- $\kappa \mathrm{B}$ dimers are usually present in the cytoplasm of most cells in an inactive form, as they bind to an inhibitor protein referred to as I $\mathrm{B} \alpha(42)$. After an inflammatory stimulus, the phosphorylation of IкB $\alpha$ triggers their degradation and the translocation of $\mathrm{NF}-\kappa \mathrm{B}$ to the nucleus, where it induces the expression of a broad variety of inflammatory genes, including cytokines, enzymes, adhesion molecules, and acute-phase proteins (43). In the present study, we noted that AIGIDP inhibited PMACI-induced NF- $\kappa$ B activation by suppressing $\mathrm{I} \kappa \mathrm{B} \alpha$ phosphorylation and its degradation.

In conclusion, of the AIGIDs, AIGID III was clearly more potently anti-allergic than the other fractions. Thus, mice treated with AIGID III were protected from the IgE-mediated PCA. The molecular mass of the novel peptide (AIGIDP) isolated from AIGID III was determined to be $1175.2 \mathrm{Da}$ according to ESI/MS spectroscopy data, and the amino acid sequence was found to be PFNQGTFAS. It was demonstrated that AIGIDP regulated the production of IL-1 $\beta$, IL- 6 and TNF- $\alpha$ in PMA plus A23187-stimulated HMC-1 cells and decreased the release of histamine. In addition, AIGIDP inhibited the activation of the JNK and NF- $\kappa$ B pathways. Therefore, we suggest that the regulation of the JNK and NF- $\kappa \mathrm{B}$ signalling pathways by AIGIDP in HMC-1 cells has the potential to be used in the prevention or treatment of mast cell-mediated allergic diseases. 


\section{Acknowledgements}

The present study was supported by the Basic Science Research Program through the National Research Foundation of Korea (NRF), funded by the Ministry of Education, Science and Technology (no. 2013R1A1A1A05013577), and was also supported by the Study for Establishment of Marine Natural Products Library, funded by the National Marine Biodiversity Institute of Korea (MABIK) and Marine Biotechnology Program (no. 20150220) funded by the Ministry of Oceans and Fisheries of Korea.

\section{References}

1. Ekanayake PM, De Zoysa M, Kang HS, Wan Q, Jee Y, Lee YH, Kim SJ and Lee J: Cloning, characterization and tissue expression of disk abalone (Haliotis discus discus) catalase. Fish Shellfish Immunol 24: 267-278, 2008

2. Zhu BW, Wang LS, Zhou DY, Li DM, Sun LM, Yang JF, Wu HT, Zhou XQ and Tada M: Antioxidant activity of sulphated polysaccharide conjugates from abalone (Haliotis discus hannai Ino). Eur Food Res Technol 227: 1663-1668, 2008.

3. Cook PA and Gordon HR: World abalone supply, markets, and pricing. J Shellfish Res 29: 569-571, 2010.

4. Jo HY, Jung WK and Kim SK: Purification and characterization of a novel anticoagulant peptide from marine echiuroid worm Urechis unicinctus. Process Biochem 43: 179-184, 2008.

5. Liu Z, Liu H, Liu X and Wu X: Purification and cloning of a novel antimicrobial peptide from salivary glands of the hard tick, Ixodes sinensis. Comp Biochem Physiol B Biochem Mol Biol 149: 557-561, 2008.

6. Byun HG and Kim SK: Purification and characterization of angiotensin I converting enzyme (ACE) inhibitory peptides from Alaska Pollack (Theragra chalcogramma) skin. Process Biochem 36: 1155-1162, 2001.

7. Erdmann K, Cheung BWY and Schröder H: The possible roles of food-derived bioactive peptides in reducing the risk of cardiovascular disease. J Nutr Biochem 19: 643-654, 2008.

8. Elias RJ, Kellerby SS and Decker EA: Antioxidant activity of proteins and peptides. Crit Rev Food Sci Nutr 48: 430-441, 2008

9. Roberts PR, Burney JD, Black KW and Zaloga GP: Effect of chain length on absorption of biologically active peptides from the gastrointestinal tract. Digestion 60: 332-337, 1999.

10. Vermeirssen V, van der Bent A, Van Camp J, van Amerongen A and Verstraete W: A quantitative in silico analysis calculates the angiotensin I converting enzyme (ACE) inhibitory activity in pea and whey protein digests. Biochimie 86: 231-239, 2004.

11. Jung WK, Qian ZJ, Lee SH, Choi SY, Sung NJ, Byun HG and Kim SK: Free radical scavenging activity of a novel antioxidative peptide isolated from in vitro gastrointestinal digests of Mytilus coruscus. J Med Food 10: 197-202, 2007.

12. Qian ZJ, Jung WK, Byun HG and Kim SK: Protective effect of an antioxidative peptide purified from gastrointestinal digests of oyster, Crassostrea gigas against free radical induced DNA damage. Bioresour Technol 99: 3365-3371, 2008.

13. Qian ZJ, Kim SA, Lee JS, Kim HJ, Choi IH and Jung WK: The antioxidant and anti-inflammatory effects of abalone intestine digest, Haliotis discus hannai in RAW 264.7 macrophages. Biotechnol Bioprocess Eng; BBE 17: 475-484, 2012.

14. Nguyen VT, Qian ZJ, Ryu B, Kim KN, Kim D, Kim YM, Jeon YJ, Park WS, Choi IW, Kim GH, et al: Matrix metalloproteinases (MMPs) inhibitory effects of an octameric oligopeptide isolated from abalone Haliotis discus hannai. Food Chem 141: 503-509, 2013.

15. Conrad ML, Renz H and Blaser K: Immunological approaches for tolerance induction in allergy. Curr Top Microbiol Immunol 352: 1-26, 2011.

16. Marsella R, Nicklin C and Lopez J: Studies on the role of routes of allergen exposure in high IgE-producing beagle dogs sensitized to house dust mites. 17: 306-312, 2006.

17. Stone KD, Prussin C and Metcalfe DD: IgE, mast cells, basophils, and eosinophils. J Allergy Clin Immunol 125: S73-S80, 2010.

18. Metz M and Maurer M: Mast cells - key effector cells in immune responses. Trends Immunol 28: 234-241, 2007.

19. Galli SJ, Maurer M and Lantz CS: Mast cells as sentinels of innate immunity. Curr Opin Immunol 11: 53-59, 1999.
20. Marshall JS: Mast-cell responses to pathogens. Nat Rey Immunol 4: 787-799, 2004.

21. Kawakami T and Galli SJ: Regulation of mast-cell and basophil function and survival by IgE. Nat Rev Immunol 2: 773-786, 2002.

22. Kapsokefalou M and Miller DD: Effects of meat and selected food components on the valence of nonheme iron during in vitro digestion. J Food Sci 56: 352-355, 1991.

23. Yu BC, Lee DS, Bae SM, Jung WK, Chun JH, Urm SH, Lee DY, Heo SJ, Park SG, Seo SK, et al: The effect of cilostazol on the expression of matrix metalloproteinase-1 and type I procollagen in ultraviolet-irradiated human dermal fibroblasts. Life Sci 92: 282-288, 2013

24. Shakoory B, Fitzgerald SM,LeeSA, Chi DS and Krishnaswamy G: The role of human mast cell-derived cytokines in eosinophil biology. J Interferon Cytokine Res 24: 271-281, 2004.

25. Kyriakis JM and Avruch J: Mammalian mitogen-activated protein kinase signal transduction pathways activated by stress and inflammation. Physiol Rev 81: 807-869, 2001.

26. Paeng SH, Park WS, Jung WK, Lee DS, Kim GY, Choi YH, Seo SK, Jang WH, Choi JS, Lee YM, et al: YCG063 inhibits Pseudomonas aeruginosa LPS-induced inflammation in human retinal pigment epithelial cells through the TLR2-mediated AKT/NF- $\mathrm{BB}$ pathway and ROS-independent pathways. Int J Mol Med 36: 808-816, 2015.

27. Yu GJ, Choi IW, Kim GY, Kim BW, Park C, Hong SH, Moon SK, Cha HJ, Chang YC, Paek KY, et al: Anti-inflammatory potential of saponins derived from cultured wild ginseng roots in lipopolysaccharide-stimulated RAW 264.7 macrophages. Int J Mol Med 35: 1690-1698, 2015.

28. Guerra A, Etienne-Mesmin L, Livrelli V, Denis S, Blanquet-Diot S and Alric M: Relevance and challenges in modeling human gastric and small intestinal digestion. Trends Biotechnol 30: 591-600, 2012.

29. Borgström B, Dahlqvist A, Lundh G and Sjovall J: Studies of intestinal digestion and absorption in the human. J Clin Invest 36: 1521-1536, 1957.

30. Mayer AMD, Rodríguez AD, Berlinck RG and Fusetani N: Marine pharmacology in 2007-8: Marine compounds with antibacterial, anticoagulant, antifungal, anti-inflammatory, antimalarial, antiprotozoal, antituberculosis, and antiviral activities; affecting the immune and nervous system, and other miscellaneous mechanisms of action. Comp Biochem Physiol C Toxicol Pharmacol 153: 191-222, 2011.

31. Ma HT and Beaven MA: Regulation of $\mathrm{Ca}^{2+}$ signaling with particular focus on mast cells. Crit Rev Immunol 29: 155-186, 2009.

32. Kemp SF and Lockey RF: Anaphylaxis: a review of causes and mechanisms. J Allergy Clin Immunol 110: 341-348, 2002.

33. Li-Chan ECY: Bioactive peptides and protein hydrolysates: research trends and challenges for application as nutraceuticals and functional food ingredients. Curr Opin Food Sci 1: 28-37, 2015.

34. Lordan S, Ross RP and Stanton C: Marine bioactives as functional food ingredients: potential to reduce the incidence of chronic diseases. Mar Drugs 9: 1056-1100, 2011.

35. Je JY, Park PJ, Kwon JY and Kim SK: A novel angiotensin I converting enzyme inhibitory peptide from Alaska pollack (Theragra chalcogramma) frame protein hydrolysate. J Agric Food Chem 52: 7842-7845, 2004.

36. Min YD, Choi CH, Bark H, Son HY, Park HH, Lee S, Park JW, Park EK, Shin HI and Kim SH: Quercetin inhibits expression of inflammatory cytokines through attenuation of NF-kappaB and p38 MAPK in HMC-1 human mast cell line. Inflamm Res 56: 210-215, 2007.

37. Okada S, Inoue H, Yamauchi K, Iijima H, Ohkawara Y, Takishima $T$ and Shirato K: Potential role of interleukin-1 in allergen-induced late asthmatic reactions in guinea pigs: suppressive effect of interleukin-1 receptor antagonist on late asthmatic reaction. J Allergy Clin Immunol 95: 1236-1245, 1995.

38. Galli SJ, Nakae S and Tsai M: Mast cells in the development of adaptive immune responses. Nat Immunol 6: 135-142, 2005.

39. Nakae S, Lunderius C, Ho LH, Schäfer B, Tsai M and Galli SJ: TNF can contribute to multiple features of ovalbumin-induced allergic inflammation of the airways in mice. J Allergy Clin Immunol 119: 680-686, 2007.

40. Sundström M, Alfredsson J, Olsson N and Nilsson G: Stem cell factor-induced migration of mast cells requires p38 mitogen-activated protein kinase activity. Exp Cell Res 267: 144-151, 2001.

41. Barnes PJ: Pathophysiology of allergic inflammation. Immunol Rev 242: 31-50, 1011, 2011.

42. Baldwin AS Jr: The NF-kappa B and I kappa B proteins: New discoveries and insights. Annu Rev Immunol 14: 649-683, 1996.

43. Barnes PJ and Karin M: Nuclear factor-kappaB: a pivotal transcription factor in chronic inflammatory diseases. N Engl J Med 336: 1066-1071, 1997. 